\title{
THE EFFECT OF BULK COMPOSITION ON SWELLING AND RADIATION-INDUCED SEGREGATION IN AUSTENITIC ALLOYS
}

\author{
by \\ T. R. Allen, J. I. Cole, N. L. Dietz, \\ Y. Wang, G. S. Was, E. A. Kenik \\ Engineering Division \\ Argonne National Laboratory-West \\ P. O. Box 2528 \\ Idaho Falls, ID 83403-2528
}

The submitted manuscript has been
created by the University of Chicago
as Operator of Argonne National
Laboratory ("Argonne") under contrac
No. W-31-109-ENG-38 with the U. S.
Department of Energy. The U.S.
Government retains for itself, and
others acting on its behalf, a paid-up
nonexclusive, irrevocable worldwide
license in said article to reproduce,
prepare derivative works, distribute
copies to the public, and perform
publicly and display publicly, by or on
behalf of the Government.

MRS 2000 Fall Meeting

Boston, MA

November 27 - December 1, 2000

*Work supported by the U.S. Department of Energy, Office of Nuclear Energy, Science and Technology, under Contract W-31-109-ENG-38. 


\section{DISCLAIMER}

This report was prepared as an account of work sponsored by an agency of the United States Government. Neither the United States Government nor any agency thereof, nor any of their employees, make any warranty, express or implied, or assumes any legal liability or responsibility for the accuracy, completeness, or usefulness of any information, apparatus, product, or process disclosed, or represents that its use would not infringe privately owned rights. Reference herein to any specific commercial product, process, or service by trade name, trademark, manufacturer, or otherwise does not necessarily constitute or imply its endorsement, recommendation, or favoring by the United States Government or any agency thereof. The views and opinions of authors expressed herein do not necessarily state or reflect those of thie United States Government or any agency thereof. 


\section{DISCLAIMER}

Portions of this document may be illegible in electronic image products. Images are produced from the best available original document. 
MRS 2000 Fall Meeting

Symposium R: Microstructural Processes in Irradiated Materials

NOV $0 \& 2000$

\title{
THE EFFECT OF BULK COMPOSITION ON SWELLING AND RADIATION-INDUCED SEGREGATION IN AUSTENITIC ALLOYS
}

\author{
T. R. Allen, J. I. Cole, and N. L. Dietz, Argonne National Laboratory-West \\ Y. Wang and G. S. Was, University of Michigan \\ E. A. Kenik, Oak Ridge National Laboratory
}

\begin{abstract}
Changes in bulk composition are known to affect both radiation-induced segregation and microstructural development, including void swelling in austenitic stainless steels. In this work, three alloys have been studied: $\mathrm{Fe}-18 \mathrm{Cr}-8 \mathrm{Ni}$ alloy (bulk composition corresponding to 304 stainless steel), $\mathrm{Fe}-18 \mathrm{Cr}-40 \mathrm{Ni}$ (bulk composition corresponding to 330 stainless steel), and $\mathrm{Fe}-$ $16 \mathrm{Cr}-13 \mathrm{Ni}$ (bulk composition corresponding to 316 stainless steel). Following irradiation with high-energy protons, the change in hardness and microstructure (void size distribution and grain boundary composition) due to irradiation is investigated. Increasing the bulk nickel concentration decreases void swelling, increases matrix hardening, and increases grain boundary chromium depletion and nickel enrichment. The analysis shows that decreases in lattice parameter and shear modulus due to radiation-induced segregation correlate with decreased void swelling and a decreased susceptibility to irradiation assisted stress corrosion cracking (IASCC). While traditional thinking on IASCC assumed RIS was a contributing factor to cracking, it may be that properly controlled RIS can be used to mitigating cracking.
\end{abstract}

\section{Introduction}

This study analyzes the effect of alloy composition on void swelling, radiation-induced grain boundary segregation, and hardening in a series of $\mathrm{Fe}-\mathrm{Cr}-\mathrm{Ni}$ alloys. $\mathrm{An} \mathrm{Fe}-18 \mathrm{Cr}-8 \mathrm{Ni}$ alloy (corresponding to 304 stainless steel) is used as the reference alloy for this project. AISI type 304 stainless steel is known to be susceptible to both swelling and irradiation assisted stress corrosion cracking (IASCC), where IASCC may be caused by grain boundary chromium depletion during irradiation. Alloying additions are made to improve the swelling and grain boundary segregation resistance relative to 304 stainless steel.

Two compositions were studied in addition to the base alloy: Fe-18Cr-40Ni (corresponding to 330 stainless steel) and $\mathrm{Fe}-16 \mathrm{Cr}-13 \mathrm{Ni}$ (corresponding to 316 stainless steel. The Fe-18Cr-40Nialloy is studied to measure grain boundary segregation in an alloy that exhibits excellent swelling resistance. The Fe-16Cr-13Ni alloy is studied to determine the effect of major element composition change between 304 and 316 stainless steel. AISI 316 is more swelling resistant [1] and more resistant to IASCC [2] than 304.

\section{Experiment}

Three separate alloys were tested. Table 1 provides the compositions of each alloy. Each alloy was cold-worked and then underwent a recrystallization anneal to obtain an average grain size of around 20 microns. Twenty-micron grains were desired because the range of damage in the proton beam used to irradiate samples is approximately forty microns. Twenty-micron grains would allow an average damage zone depth covering two grains. 
Table 1. Alloy concentrations (at $\%$ )

\begin{tabular}{|l|c|c|c|c|}
\hline Alloy Designation & $\mathrm{Fe}$ & $\mathrm{Cr}$ & $\mathrm{Ni}$ & $\mathrm{Mn}$ \\
\hline $\mathrm{Fe}-18 \mathrm{Cr}-8 \mathrm{Ni}-1.25 \mathrm{Mn}$ & 71.5 & 19.2 & 7.8 & 1.1 \\
\hline $\mathrm{Fe}-18 \mathrm{Cr}-40 \mathrm{Ni}-1.25 \mathrm{Mn}$ & 38.9 & 19.6 & 40.2 & 1.2 \\
\hline $\mathrm{Fe}-16 \mathrm{Cr}-13 \mathrm{Ni}-1.25 \mathrm{Mn}$ & 69.8 & 16.7 & 12.2 & 1.2 \\
\hline
\end{tabular}

Samples are irradiated using $3.2 \mathrm{MeV}$ protons at $400^{\circ} \mathrm{C}$ to 1 displacement per atom (dpa). Following irradiation, samples are analyzed using a transmission electron microscope (TEM). Swelling is characterized by measuring the void size distribution in the TEM samples. Void distributions were measured using a JEOL 2010 TEM. Sample thickness for cavity density measurements was determined using convergent beam electron diffraction (CBED). Radiationinduced grain boundary segregation is measured using a Phillips CM200 field emission gun scanning transmission electron microscope (FEG-STEM). Microhardness measurements are performed on irradiated alloys to estimate the effect of irradiation on strength. Vickers hardness was measured using a Vickers Microhardness Tester (Micromet-II). A total of 30 to 50 indents at a load of $25 \mathrm{~g}$ were applied on the TEM bar in both the irradiated region and the unirradiated region of the sample.

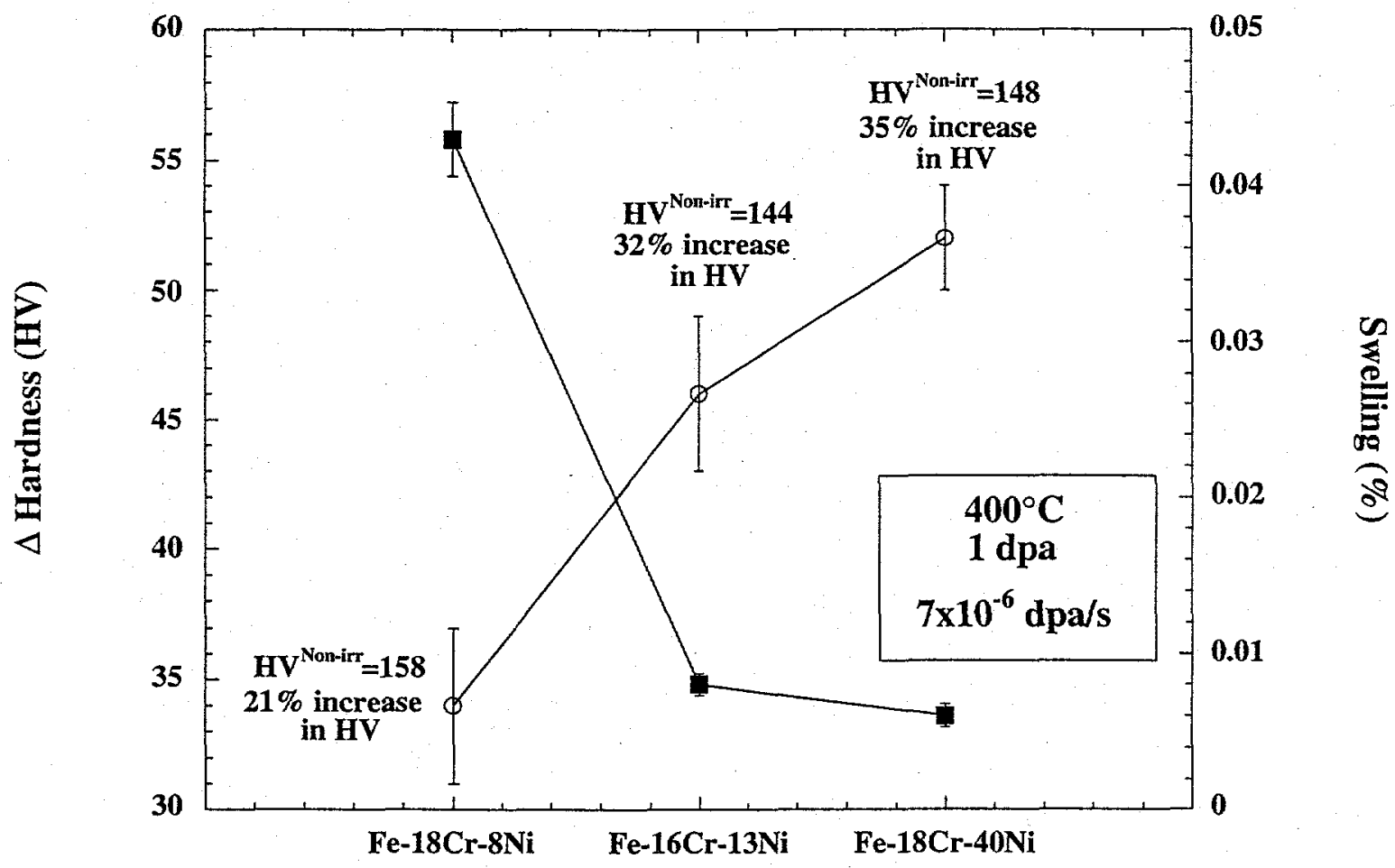

Alloy

Figure 1. Hardness change and swelling as a function of alloy composition. 


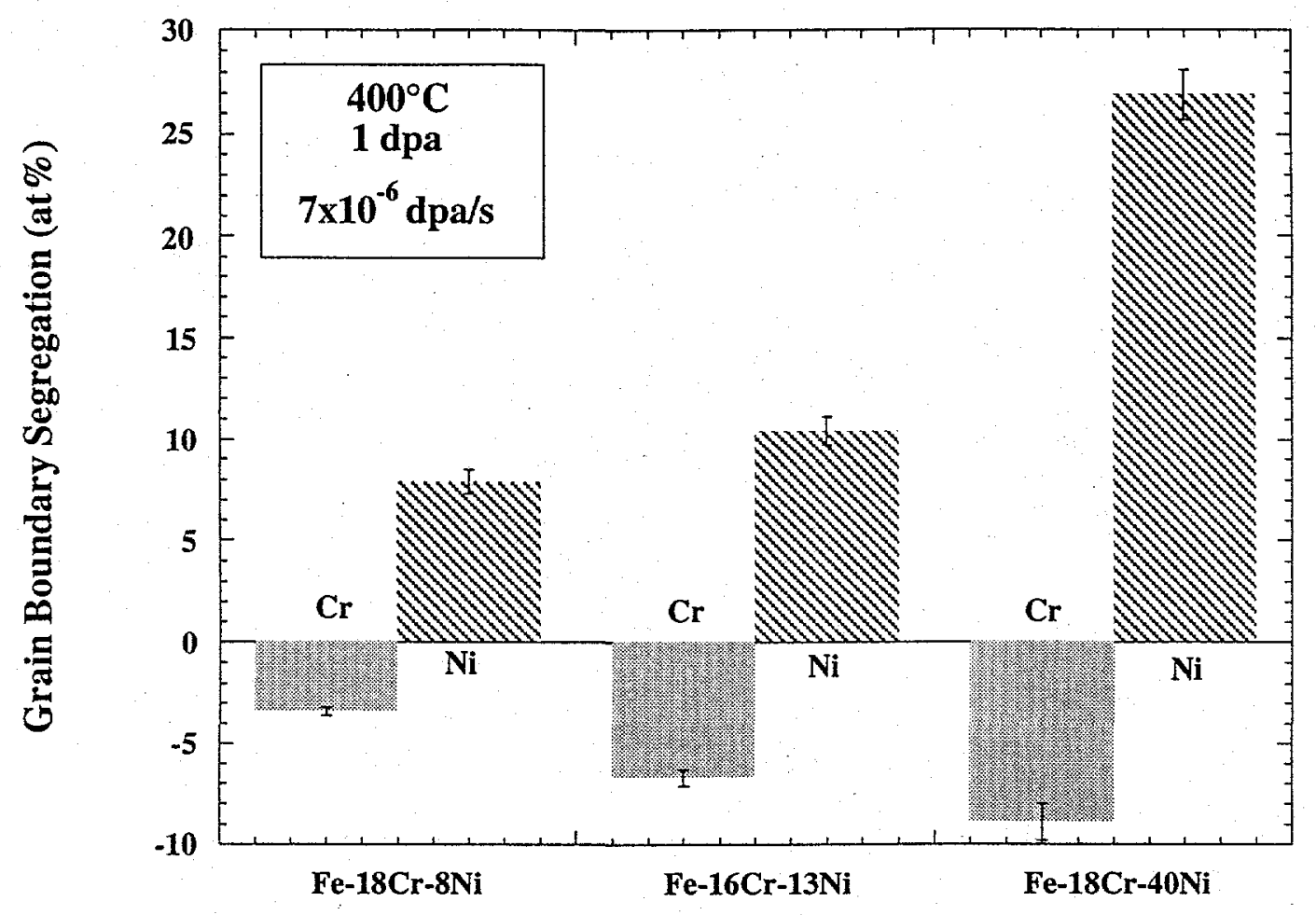

Alloy

Figure 2. Grain boundary segregation as a function of alloy composition.

\section{Results and Discussion}

The void swelling and increase in hardness for each alloy is plotted in Figure 1. The increase in hardness is greatest in the $\mathrm{Fe}-18 \mathrm{Cr}-40 \mathrm{Ni}$ alloy and smallest in the $\mathrm{Fe}-18 \mathrm{Cr}-8 \mathrm{Ni}$ alloy. The swelling is greatest in the $\mathrm{Fe}-18 \mathrm{Cr}-8 \mathrm{Ni}$ alloy and smallest in the $\mathrm{Fe}-18 \mathrm{Cr}-40 \mathrm{Ni}$ alloy. As a general trend, increasing the bulk nickel concentration mitigates swelling but increases the hardening. The grain boundary chromium depletion and nickel enrichment are plotted in Figure 2. The chromium depletion and nickel enrichment are smallest in the $\mathrm{Fe}-18 \mathrm{Cr}-8 \mathrm{Ni}$ alloy and greatest in the $\mathrm{Fe}-18 \mathrm{Cr}$ $40 \mathrm{Ni}$ alloy.

\section{Radiation-induced segregation and swelling}

Previous work has shown that changes in bulk composition can reduce void swelling by increasing the average vacancy diffusivity (to reduce the void nucleation rate) and by decreasing the vacancy diffusivity at a void surface due to RIS (to reduce the void growth rate) [3]. The changes in the grain boundary shear modulus and lattice parameter caused by RIS near a void surface also affect the ability for voids to nucleate and grow. Wolfer et al. showed that a compositional change which increases the shear modulus or lattice parameter locally around a void embryo causes the void to become a preferential sink for vacancies, thus increasing the void nucleation rate [4-6]. For $\mathrm{Fe}-\mathrm{Cr}-\mathrm{Ni}$ alloys with compositions near 304/316 SS, the lattice parameter and shear moduli increase with increasing $\mathrm{Cr}$ concentration and decrease with increasing Ni concentration [4]. For $304 / 316$ stainless steel, RIS causes $\mathrm{Cr}$ to deplete and $\mathrm{Ni}$ to enrich around a void during irradiation. These changes in lattice parameter and shear modulus would tend to mitigate void nucleation. 
Bates et al. measured the partial molar volumes for the constituents of 316 stainless steel [7]. For 316 stainless steel, Fe and $\mathrm{Ni}$ are undersized and $\mathrm{Cr}, \mathrm{Mn}$, and $\mathrm{Mo}$ are oversized relative to the average lattice atom. The change in average lattice volume in the vicinity of the grain boundary can be estimated using:

$$
\mathrm{dV}=\sum_{\mathrm{i}} \overline{\mathrm{v}}_{\mathrm{i}} \mathrm{dn_{ \textrm {i } }}
$$

where $\mathrm{dV}$ is the change in volume, $\overline{\mathrm{v}}_{\mathbf{i}}$ is the partial molar volume of the component, and $\mathrm{dn}_{\mathbf{i}}$ is the change in the number of grams per mole of component $i$. The change in volume near the void due to RIS was estimated for the alloys in this study. For these estimates, the partial molar volumes are those measured by Bates et al. and the change in grams per mole is taken to be the difference between the measured grain boundary composition (assuming segregation to voids is comparable to segregation at grain boundaries) and the bulk of 316 stainless steel. The swelling as a function of change in grain boundary volume is plotted in figure 3. As predicted by Wolfer et al., as the magnitude of the change in grain boundary volume becomes laiger (change in grain boundary volume becomes more negative), swelling is reduced.

\section{Radiation-induced segregation and IASCC}

Two effects of radiation on microstructure have been hypothesized to contribute to IASCC: $\mathrm{Cr}$ depletion leading to decreased grain boundary corrosion resistance and matrix hardening leading to a grain boundary weakened relative to the matrix. Support for the matrix hardening contribution was provided by Was and Bruemmer who showed that IGSCC susceptibility correlated reasonably well with yield stress [8]. Comparing the Fe-18Cr-8Ni (corresponding to 304 stainless steel) and $\mathrm{Fe}-16 \mathrm{Cr}-13 \mathrm{Ni}$ (corresponding to 316 stainless steel) alloys, moving toward the 316 composition causes greater hardening (figure 1) and greater $\mathrm{Cr}$ depletion (figure 2). Greater hardening and greater $\mathrm{Cr}$ segregation should make 316 more susceptible to IASCC. Additionally, 316 has a greater stacking fault energy than 304, making dislocation channeling easier, possibly leading to a concentration of stress at the grain boundary and an increased probability of grain boundary cracking. Yet 316 is typically less susceptible than 304 to IASCC [2]. Some factor may be compensating against the chromium depletion and matrix hardening to strengthen the boundary.

Figure 3 plots the change in hardness, the grain boundary $\mathrm{Cr}$ depletion, and the grain boundary nickel enrichment versus the change in grain boundary volume for all three alloys. As the change in grain boundary volume becomes more negative, the hardening and $\mathrm{Cr}$ depletion increase, theoretically making the alloy more susceptible to IASCC. But Cookson et al. found that increasing Ni content decreased IASCC susceptibility [9]. Decreased IASCC susceptibility may be related to the net grain boundary volume decrease. The decrease in grain boundary volume may strengthen the boundary. As explained above, the lattice parameter and shear moduli decrease with decreasing $\mathrm{Cr}$ concentration and with increasing $\mathrm{Ni}$ concentration. $\mathrm{Cr}$ depletes and $\mathrm{Ni}$ enriches at the boundary during irradiation. The smaller modulus and smaller solute atoms caused by RIS may strengthen the boundary against cracking. While typical studies of IASCC assumed RIS was a contributing factor to cracking, it may be that properly controlled RIS can be used as a mitigating factor. If this theory is correct, the $\mathrm{Fe}-18 \mathrm{Cr}-40 \mathrm{Ni}$ alloy may be quite resistant to IASCC, but the large amount of matrix hardening may make this alloy unacceptable for reactor use. 


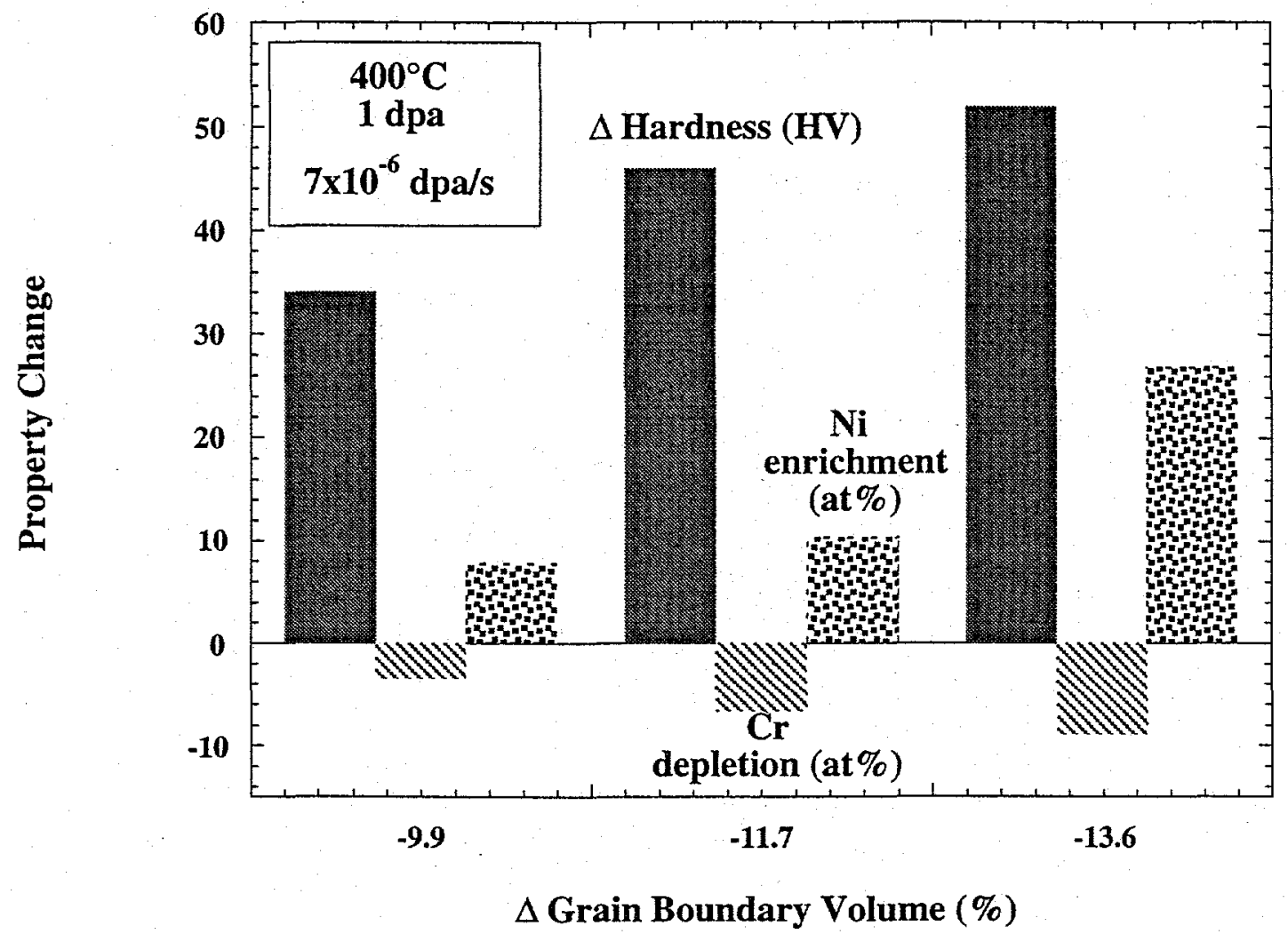

\section{Conclusions}

Void swelling, hardening, and radiation-induced segregation have been studied in three austenitic stainless steel alloys (Fe-18Cr-8Ni, $\mathrm{Fe}-16 \mathrm{Cr}-13 \mathrm{Ni}$, and $\mathrm{Fe}-18 \mathrm{Cr}-40 \mathrm{Ni}$ ). Increasing the bulk nickel concentration decreases void swelling, increases matrix hardening, and increases grain boundary chromium depletion and nickel enrichment. Analysis of the data shows that radiationinduced segregation to void surfaces reduces void swelling. One mechanism for this reduction in swelling may be the reduction in lattice parameter and shear modulus that occurs due to RIS. Alloys that show the greatest matrix hardening and chromium depletion are those that are less susceptible to IASCC, contrary to common thought. The reduction in lattice parameter and shear modulus that occurs due to RIS at the grain boundary may strengthen the boundary against IASCC. While traditional thinking on IASCC assumed RIS was a contributing factor to cracking, it may be that properly controlled RIS can be used as a mitigating factor.

\section{Acknowledgements}

Research at the Oak Ridge National Laboratory ShaRE User Facility was sponsored by the Division of Materials Sciences and Engineering, U. S. Department of Energy under contract DEAC05-00OR22725 with UT-Batelle, LLC., and through the SHaRE Program under contract DEAC05-76OR00033 with Oak Ridge Associated Universities. Work supported under contract W31-109-Eng-38 with the Department of Energy.

\section{References}


[1] F. A. Garner, Irradiation Performance of Cladding and Structural Steels in Liquid Metal Reactors, in Materials Science and Technology, A Comprehensive Treatment, Vol 10A Nuclear Materials, Eds., R. W. Cahn, P. Haasen, and E. J. Kramer, (VCH Weinheim, 1994).

[2] Y. Tanaka, S. Suzuki, M. Kodama, S. Nishimura, K. Fukuya, H. Sakamoto, K. Nakata, and T. Kato, Proceedings of the Eighth International Symposium on Environmental Degradation of Materials in Nuclear Power Systems-Water Reactors, American Nuclear Society, 1997, pp.803-811.

[3] T. R. Allen, J. T. Busby, G. S. Was, and E. A. Kenik, Effects of Radiation on Materials, 19th International Symposium, ASTM STP 1366, M. L. Hamilton, A. S. Kumar, S. T. Rosinski, and M. L. Grossbeck, Eds., American Society for Testing and Materials, 1999.

[4] W. G. Wolfer, F. A. Garner, et al. Effects of Radiation on Materials: Eleventh Conference, ASTM STP 782, American Society for Testing and Materials, (1982) pp.1023-1041.

[5] W. G. Wolfer and L. K. Mansur, J. Nucl. Mater. 91 (1980). 265-276.

[6]A. Si-Ahmed and W. G. Wolfer Effects of Radiation on Materials: Eleventh Conference, ASTM STP 782, American Society for Testing and Materials (1982), pp.1008-1022.

[7] J. F. Bates and J. L. Straaslund, Quarterly Progress Report, HEDL-TME-73-25 (November, December, January 1973).

[8] G. S. Was and S. M. Bruemmer, J. Nucl. Mater., 216 (1994) 326.

[9] J. M. Cookson, D. L. Damcott, G. S. Was, and P. L. Andresen, Proc. Sixth Int. Symp. on Env. Deg. Mat Nucl Power Syst Water React Proceedings of the 6th International Symposium on Environmental Degradation of Materials in Nuclear Power Systems-Water Reactors, San Diego, CA (1993), 573-581. 